also agree with him in considering collars and stays, and backwards and spinal supports to be worse than useless, where the unly safe mode of treatment must be based on a position affording perfect rest. I am, $\mathrm{Sir}, \& \mathrm{c} . \& \mathrm{c}$.

Low ther Arcade, April 30, 1839.

Chas. Verral.

\section{INQUESTS IN MIDDLESEX.}

\section{POST-MORTEM EXAMINATION}

\section{or $A$}

\section{MALE INFANT}

\section{Found Dead in Clarendon-place, Hyde Park.}

THE body was discovered on Saturday morning, April 20th, at about eight o'clock, carefully packed up in a deal box, appa. rently made for the purpose, with a lid of the same material, and the whole was covered with brown paper, by which the action of the external air was pretty effectually excluded. It was in a flexed position, upon the right side, and, without removing it from the box, presented a portion of the left side of the neck, denuded of its cuticle, with a florid red, and moist surface, around which there was a margin of bluish green and white mould, the same kind of mould existiog in patches over the outer surface of the left buttock and thigh, the front and uppermost part of the thorax, and the whole of the left cheek. The portion of the umbilical chord remaining attached to the abdomen was now observed to be unnsually long, considerably shrunk, not at all desiccated, and of a violet colour, as from incipient putrefaction. No further remarks were made at this time, but the box, with its contents, was given into the safe custody of the police, to await the coroner's inquest.

On Wednesday morning, April 24th, the following appearances were noted :-

Weight of the body seven pounds nine ounces avoirdupois; length twenty-one inches and a half. (If the head, the occipito-frontal diameter measured four inches and a half; from one parietal bone to the other three inches and a balf; the circumference taken over the occipital tuberosity and the frontal sinuses thirteen inches and a half; the anterior fontanelle measured about one inch from each parietal bone to its opposite frontal bone; the posterior fontanelle was nearly closed; the cranium was altogether as firm as usual at the natural period of birth. The thorax, to ocular inspection, and compared with the size of the child, was small, and not very well formed; it was sufficiently wide at its base, with the sternum elevated, but narrow at its apex. The shoulders measured four inches and three-quarters across. There were no marks whatever about the child indicating difficult or preternatural parturition. The general surface, with the exception of its denuded and moulded portions, presented a fresh appearance, with sugillations on the back and dependant parts. The entire scalp was of a remarkably vivid red colour, and plentifully covered with long dark hair; in this situation, and under the mould on the surface of the body, the cuticle was very easily detached, and on removing it the moist cutis was of a florid red colour. This was not the case in other parts ; the moulded patches were surrounded by a dark brown, well-defined areola, about three lines broad, and this, again, by a light purple shade, about twice the width. The mould, examined with a powerful microscope, exhibited no signs of mineral crystallisation, but was of a vesicular structure; the rest of the surface was perfectly free from the unctuous coating peculiar to new-born infants. The eyelids were closed, prominent, somewhat puffy, and their inner surface of an uniform dark-red colour; the tunica adnata had several dark-red spots, as if ecchymosed; decomposition had so far ad. vanced that the pupil could not be discern. ed. The remaining umbilical chord was seven inches and three-quarters long, twisted, and tied on itself into a single knot, about two inches and a half from the abdomen; its extremities were either torn or cut very irregularly. The centre of the body was three-quarters of an inch above the um. bilicus. The testicles were in the scrotum. The nails protruded beyond the fingers and toes. In all other respects the external formation was perfect and well-proportioned.

Immediately on opening the thorax the lungs were observed to be of a pale bright. scarlet colour over the whole extent of their surface; they covered the sides and arch of the diaphragm, leaving only a small strip of its anterior border exposed. The lower margins of the left upper and right middle lobes were neither sharp nor perfectly rounded; there were two or three vesicles upon their surface, about the size of half a kidney-bean, split longitudinally, and, here and there, between the lobules, the mem. brane was distended with air; they were crepitant throughout their substance. On incision they presented the same brightscarlet colour, and by slight pressure blood oozed freely from their vessels, and froth from innumerable nearly invisible orifices; being isolated as completely as possible from the surrounding parts, they weighed 900 grains, or in the proportion of 1 to $64 \frac{1}{2}$, compared with the weight of the body. When thrown into common water, before the heart was detached, they floated close under its surface; after the removal of the heart they floated with a small portion above the surface of the water; when cut 
into very small pieces, each piece floated, and no degree of compression could malie them sink. The diaphragm was molerately arched.

The foramen ovale was completely open. The ductus arteriosus was collapsed and empty, five-eighths of an inch long, its diameter less thau half that of the pulmonary artery, and somewhat smaller than that of either of its lateral branches; it was a little contracted at a point one-third distant from the pulmonary artery. The ductus venosus, umbilical vein, and umbilical arteries, were collapsed throughout their extent, but still pervious. The veins in the body generally were filled with fluid blood.

The $l i p s$, and the mucous membrane lining the interior of the mouth, were of an extremely dark-red colour, the latter being covered with what appeared to be a thick white secretion; the tongue was protruded against the inner surface of the lips, and partially between them; its base, as also the soft palate and upper portion of the oesophagus and larynx, were extremely vascular; the epiglottis was codematous; the lower portion of the oesophagus was healthy, with its epithelium entire; the stomach was collapsed, extremely soft or gelatinous, and contained only a very small quantity of a thin, reddish fluid. On chemical examination this flaid gave no reason to suspect the existence of any corrosive or poisonous substance. The drodenum $w$ as in nearly the same condition as the stomach; the gallbladder was collapsed and nearly empty, its internal surface being only thinly coated with a thick dark-brown. fluid, not at all resembling bile; the small intestines were much less softened than the stomach and duodenum, they were throughout contracted and wrinkled, and contained only a very small quantity of a mass resembling meconium in consistence, but of a dull, pale, straw colour; the large intostines, from the cocum to the commencement of the sigmoid closure of the colon, were completely filled with a similar pale, dull, straw-coloured viscons mass. At the spot last mentioned this mass abruptly assumed the usual darkgreen colour of meconium; it was rather more fluid, and filled to distention the remaining portion of the large intestines to the anus; at the external orifice of the anus there was a small quantity of meconium. flse bladder was empty and contracted.

On raisin the ralvarium, the brain was found extremely soft, the simuses contdined fluid blood; the membranes of the left hemisphere were very vascular; there was shoht extravasation of blood on its surface, and a small quantity of blood was eflused into the bony fossa which supports the middle lobe; the membranes of the right hemisphere were less vascnlar; the cerebellum, medulla oblongata, and medulla spinalis, exhibited no unusual appearances.

No. 819.
The more important inferences to be drawn from the above description are the following :-

1. That the period from the birth of the child to the finding of the body may have been several weeks.

2. That the child had obtained the full period of its foetal existence.

3. That the child was born alive.

4. That the child was perfectly formed, and that although its chest and lungs were somewhat smaller in proportion to its bulk and weight than the usual average, it was, nevertheless, healthy and vigorous.

5. That no educated midwife was present at its birth.

6. That it lived but a very short time.

7. That it did not die from hremorrhage, or from the eflects of cold.

8. That the appearances are quite compatible witl death from suffocation.

9. That some of the appearances on the exterior of the body and about the lips and mouth, lead to a supposition that ithad been scalded with water, or some other fluid, during life, but that it is by no means certain that they were not the result of putrefac. tion.

39, Albion-street, Hyde-park,

Henry Ancel. April 26, 1839.

\section{FYYDROPHOBIA TWENTY'SEVEN MONTHS AFTER THE BITE.}

FNORMOUS DOSES OF

\section{CROTON OIL AND PRUSSIC :ACID.}

SIR :-As hydrophobia is, happily, a disease of anything but frequent occurrence, and, as from the mysteriousness of its character, its ireatment has been, almost necessarily, conducted on principles empirical rather than philosophical, 1 cannot help thinking that it becomes the duty of every practitioner who meets with a case, to give his professional brethren the results of the treatment, whether successful or otherwise ; and especially if that treatment possess anything of novelty; and still more so, if it appear to have imparted any new or peculiar features to the phenomera which ordinarily characterise this awful malady. If, therefore, you deem the following case deserving a place in your payes ils insertion will oblige yours very truly,

$$
\begin{gathered}
\text { 113, Dale-street, Liverpool, } \\
\text { A pril, } 1839 .
\end{gathered}
$$

Frederick Cripps.

Mrs. H. (a respectable innkeeper's wife) was bitten on the face in the November of 1836 , by a little terrier dog, which, from a variety of circumstances, there is every rea. son to believe was mad. The wound was 